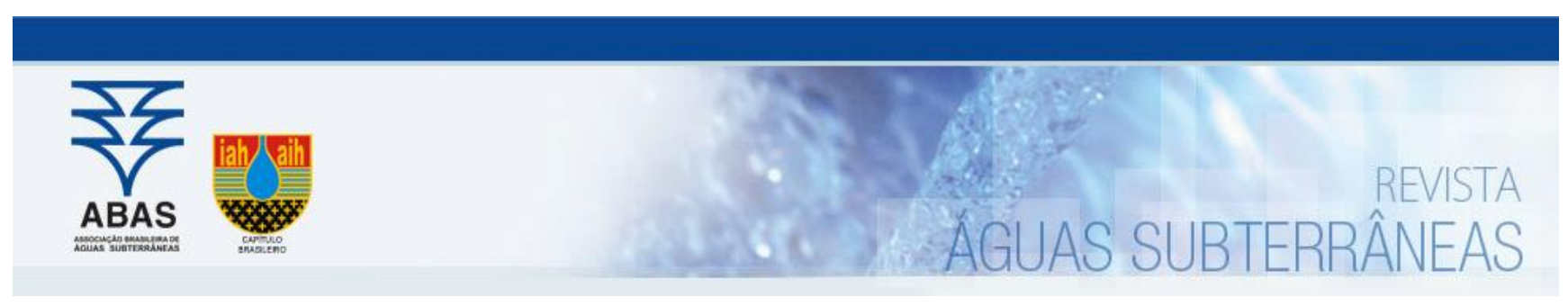

Artigos

\title{
Estabelecimento de valores de background geoquímico de parâmetros relacionados a contaminação por carvão
}

\section{Establishment of geochemical background values of parameters related to coal contamination}

\author{
Gustavo Simão1,2; Jader Lima Pereira2; Nadja Zim Alexandre3; Sergio Luciano Galatto2; Antonio Pedro Viero1 ${ }^{\square}$ \\ 1 Universidade Federal do Rio Grande do Sul (UFRGS), Porto Alegre, RS \\ 2 Universidade do Extremo Sul Catarinense (UNESC), Criciúma, SC \\ 3 Instituto do Meio Ambiente de Santa Catarina (IMA) \\ $\bowtie$ gustavosimao@unesc.net, jaderlimapereira@gmail.com, nadjaalexandre@ima.sc.gov.br, sga@unesc.net, antonio.viero@ufrgs.br
}

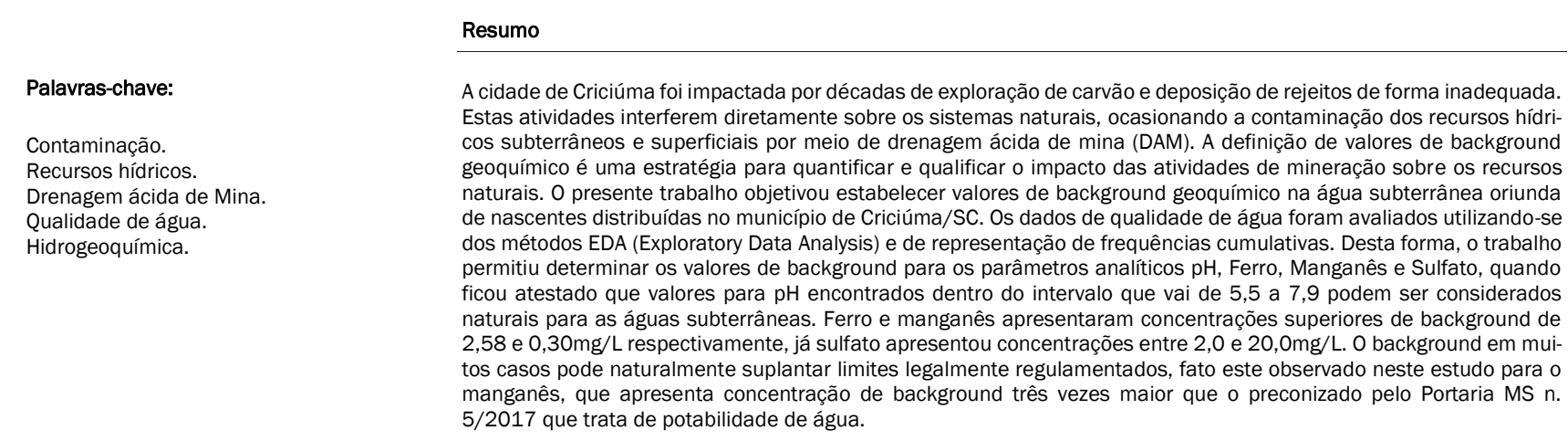

Keywords:

Abstract

Contamination.

Water resources.

Mine acid drainage.

Water quality.

Hydrogeochemistry.

The city of Criciúma was impacted by decades of coal mining exploration and tailings disposal. These activities directly interfere with natural resource systems, causing the contamination of ground and surface water resources through acid mine drainage (DAM).The definition of geochemical background values is a strategy to quantify and qualify the impact of mining activities on natural resources. The present paper aimed to establish geochemical background values in groundwater from springs distributed in the city of Criciúma/SC. The water quality data were evaluated using the Exploratory Data Analysis (EDA) and cumulative frequency representation methods. Thus, the work allowed to determine the background values for the analytical parameters pH, Iron, Manganese and Sulphate, when it was confirmed that values for $\mathrm{pH}$ found within the range of 5.5 to 7.9 can be considered normal for the groundwater. Iron and manganese had background concentrations of 2.58 and $0.30 \mathrm{mg} / \mathrm{L}$ respectively, while sulfate had concentrations between 2.0 and $20.0 \mathrm{mg} / \mathrm{L}$. The background in many cases can of course supplant legally regulated limits, a fact observed in this study for manganese, which has a background concentration three times higher than that recommended by MS Ordinance n. 5/2017 which deals with water potability.

DOI: http:/dx.doi.org/10.14295/ras.v33i2.29207

\section{INTRODUÇÃO}

Atividades antrópicas são responsáveis pela introdução de diversos contaminantes (p.ex. As, $\mathrm{Pb}, \mathrm{Cd}, \mathrm{Hg}$, dentre outros) no meio ambiente. $O$ acréscimo de cargas contaminantes ao meio, traz consigo a necessidade de se compreender as consequências que tais ações e/ou atividades podem acarretar ao ambiente. Com isso, as investigações relacionadas ao processo de contaminação do ar, água, solo e sedimentos têm se tornado crescentes em todo o mundo, tornando assim, o uso do termo background geoquímico cada vez mais frequente em estudos ambientais (MATSCHULLAT et al., 2000).

O estabelecimento de valores de background geoquímico como uma medida para distinguir concentrações naturais de um elemento (geogênica e/ou biogênica) e a influência das atividades antrópicas representa um dos assuntos mais importantes das ciências ambientais recentes (RODRIGUES; NALINI Jr., 2009). A relação entre as alterações naturais e as proporcionadas pela ação antrópica nas espécies químicas é 
uma questão que envolve implicações nas diversas áreas do conhecimento como a geologia, toxicologia, biologia, hidrogeologia dentre outras.

Neste contexto, diversas instituições do mundo têm instituído valores de referência, de maneia a avaliar eventuais danos causados ao meio ambiente por atividades antropogênicas, como maiores exemplos podem ser citados o Intervention values and target values: Soil quality standards (VROM, 1994) holandês e o Soil Screening Guidance da Agência de Proteção Ambiental dos Estados Unidos (USEPA, 1996).

No caso do Brasil, a responsabilidade pela definição dos valores de referência para avaliação da água superficial, solo, água subterrânea e sedimentos é do Conselho Nacional de Meio Ambiente (CONAMA), o qual o faz por meio das suas resoluções (BRASIL, 2005; 2008; 2009; 2011).

Dentre as atividades antrópicas que contribuem significativamente para a alteração das concentrações naturais, destacam-se as atividades mineiras. Estas, causam impacto direto sobre os sistemas naturais, interferindo na disponibilidade de recursos, e em muitos casos resultando em efeitos irreversíveis. Em Santa Catarina, especialmente, na Bacia Carbonífera Catarinense, a mineração resultou em cerca de $786 \mathrm{~km}$ de rios comprometidos por influência da drenagem ácida de mina (DAM), perfazendo porções significativas das bacias dos rios Araranguá, Tubarão e Urussanga (SCHNEIDER, 2006).

Neste sentido, a DAM representa um dos principais desafios para a explotação de qualquer recurso mineral que tenha a si associado, minerais sulfetados, em especial no que diz respeito, à contaminação dos recursos hídricos subterrâneos e superficiais (GOMO; VERMEULEN, 2013). Os aquíferos afetados por esta atividade caracterizam-se por elevada acidez, bem como por elevados teores de ferro, manganês e sulfetos.

Além da DAM, a deposição de rejeitos piritosos de forma inadequada gerou e continua gerando sérios problemas ambientais, associados a contaminação tanto do solo quanto da água superficial e subterrânea (CAMPOS; ALMEIDA; SOUZA, 2003). Mesmo após o término das operações de extração e beneficiamento do carvão, a geração de poluentes continua ativa, sendo extremamente danosa ao meio ambiente por décadas, e alguns casos, centenas de anos (ALEXANDRE, 1996).

Este cenário de intensa degradação colocou a Bacia Carbonífera Catarinense entre as 14 Áreas Críticas Nacionais para efeito de controle da poluição e conservação da qualidade ambiental (BRASIL, 1980; RAVAZZOLLI, 2013).
Os valores de referência são em tese, concentrações naturais (valores de background) de uma substância. Entretanto, tais valores de referência estabelecidos a nível nacional (BRASIL, 2005; 2008; 2009; 2011) ou internacional (VROM, 1994 e USEPA, 1996), podem em muitos casos, não corresponder à realidade local, uma vez que esta é influenciada por fatores litológicos, pedológicos e climáticos.

Neste sentido, o presente trabalho pretendeu estabelecer valores de background geoquímico na água subterrânea oriundas de nascentes para os parâmetros analíticos pH, Ferro, Manganês e Sulfatos, uma vez que estes representam os principais indicadores de contaminação ligada a atividades da cadeia de produção do carvão.

\section{MATERIAIS E MÉTODO}

\section{1. Área de estudo}

A área de estudo compreende o município de Criciúma, situado no sul do estado de Santa Catarina, a uma latitude de $28^{\circ} 42^{\prime} 30$ "S e longitude de $49^{\circ} 22^{\prime} 30^{\prime \prime} \mathrm{W}$, tendo como confrontações, ao norte os municípios de Cocal do Sul, Morro da Fumaça e Siderópolis, ao sul com Maracajá e Araranguá, ao leste Içara e a oeste Forquilhinha e Nova Veneza (Figura 1). A figura 1 apresenta a espacialização das nascentes avaliadas, em azul as nascentes utilizadas nos tratamentos estatísticos e em vermelho as descartadas devido a indicação de contaminação por atividades da cadeia produtiva de carvão.

O cenário geomorfológico do município de Criciúma é dividido em três domínios morfoestruturais (Figura 2): i) Embasamentos em Estilos Complexos; ii) Bacias e Coberturas Sedimentares; iii) Depósitos Sedimentares (GAPLAN, 1986). O domínio Embasamentos em Estilos Complexos apresenta pequenas ocorrências na porção nordeste da área de estudo, sendo caracterizado por ocorrências do Granito Imaruí Capivarí, o qual se caracteriza por sieno e monzogranitos, cor cinza a rosa, frequentemente leucocráticos. 0 domínio Bacias e Coberturas

Sedimentares é representado pela região geomorfológica denominada Depressão do Sudeste Catarinense, a qual ocupa toda a porção norte da área e apresenta significativas ocorrências na porção inferior, com relevo colinoso e vales ora encaixados ora abertos. Disseminados nesta porção ocorrem relevos residuais de topo plano, mantidos por horizontes mais resistentes da rocha sedimentar ali presente (SILVA; LEITES, 2000). 
Figura 1 - Localização da área de estudo, com destaque para as nascentes avaliadas

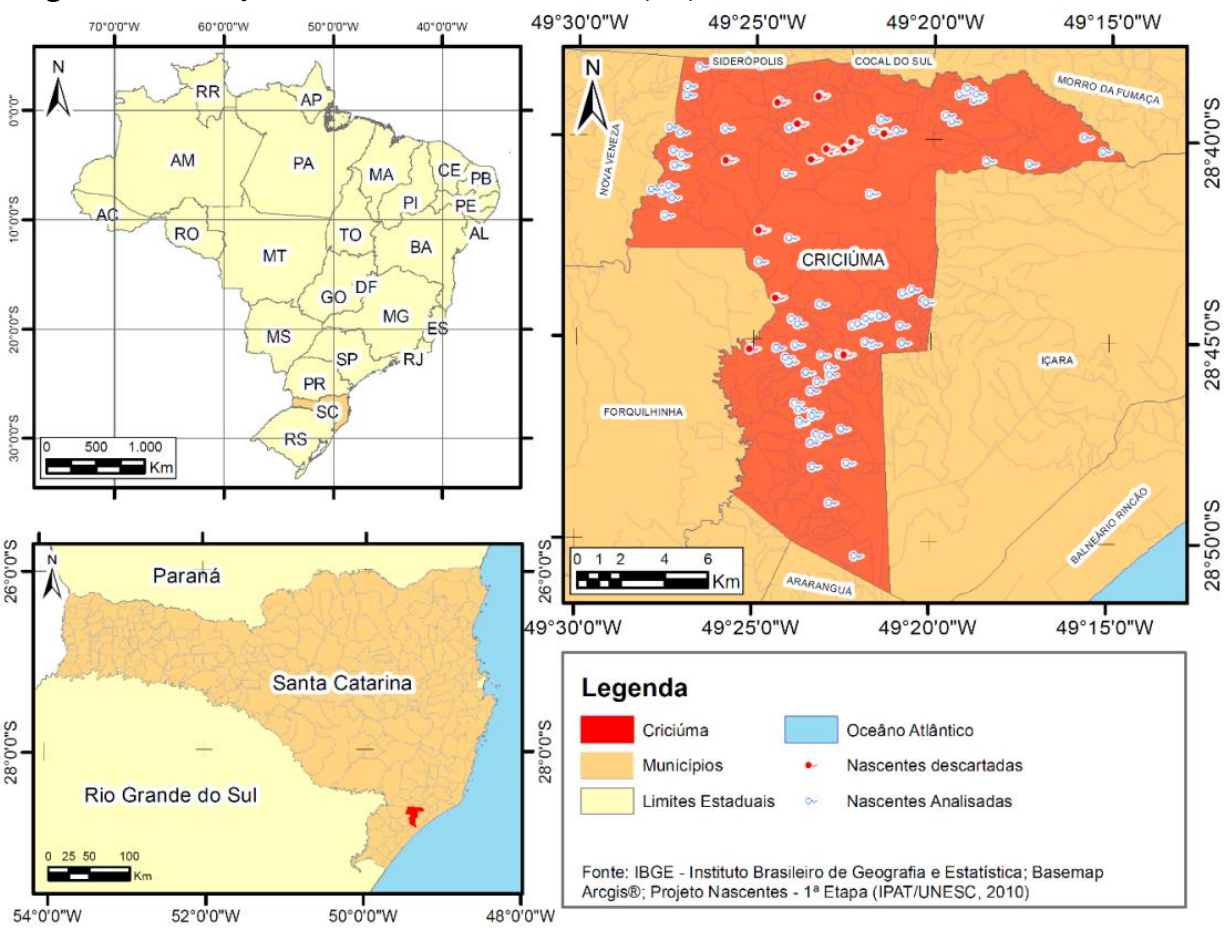

Figura 2 - Domínios morfoestruturais

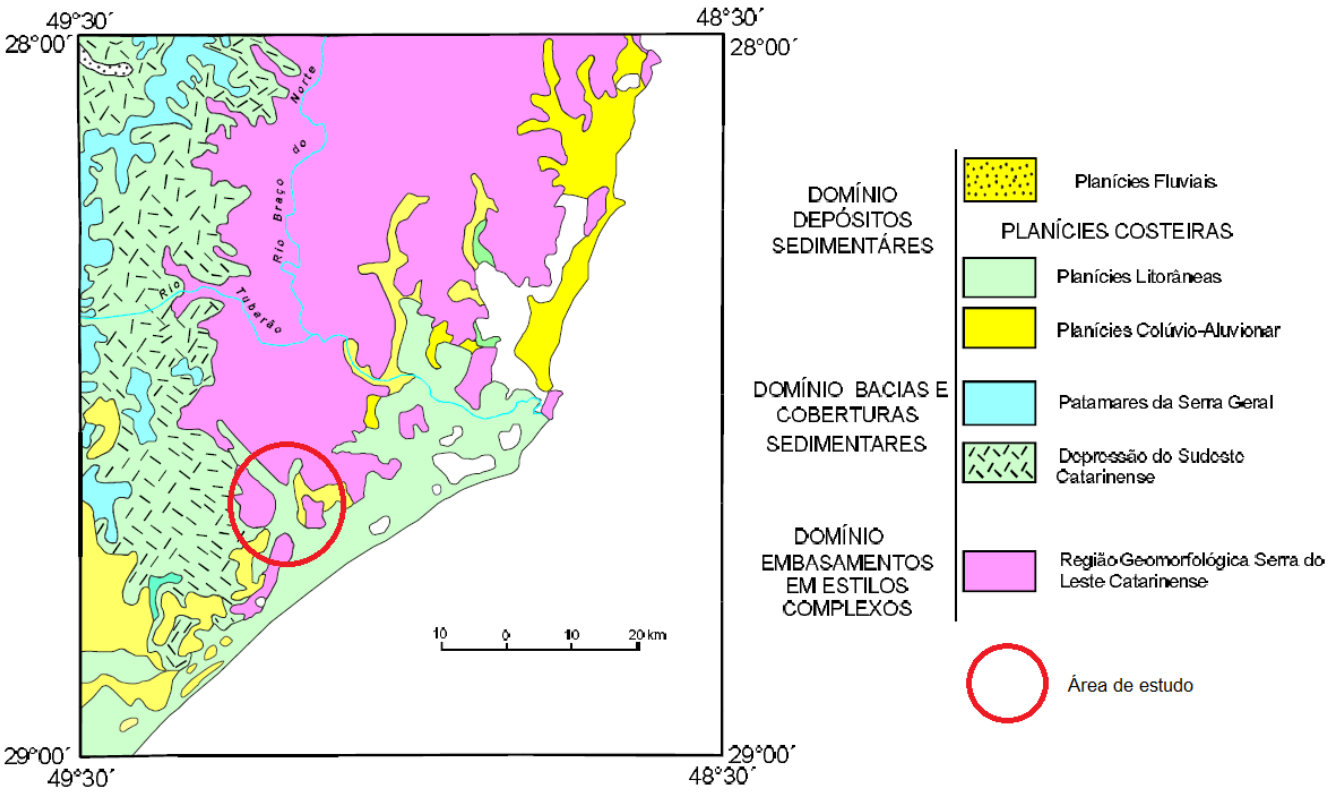

Fonte: Modificado de GAPLAN (1986)

Este domínio encontra-se inserido no contexto geológico da borda sul-sudeste da Bacia do Paraná, onde ocorrem às formações sedimentares Rio Bonito, Palermo, Irati, Rio do Rasto além da ocorrência de afloramentos de rochas vulcânicas extrusivas e intrusivas da Formação Serra Geral (Figura 3A).

A Formação Rio Bonito caracteriza-se por apresentar um conjunto de rochas areníticas (arenitos finos a grossos - cinza-esbranquiçados, localmente conglomeráticos, com estratificações paralelas, cruzadas tabular e acanalada; arenitos sigmoidais; e arenitos quartzosos) associados à pelitos e camadas de carvão (SCHNEIDER et al., 1974).
A Formação Palermo, é caracterizada por um espesso pacote de ritmitos com interlaminação de areia, silte e argila, e intenso retrabalhamento por ondas. A alternância de tonalidades claras e escuras evidência a intercalação de leitos arenosos e siltico-argilosos, respectivamente (SCHNEIDER et al., 1974).

A Formação Irati caracteriza-se por ser essencialmente pelítica, sendo constituída, na sua base, por folhelhos e siltítos cinza-escuro, eventualmente cinza-claro a azulados. Quando intemperizados, os folhelhos adquirem tons amarelados, micáceos, mostrando desagregação conchoidal. No seu topo é 
formada por um pacote de folhelhos cinza-escuro a pretos, intercalados com folhelhos pirobetuminosos associados a lentes de margas creme a cinza-escuro, dolomíticas (SCHNEIDER et al., 1974).

A Formação Rio do Rasto apresenta um membro inferior, constituído por arenitos finos bem selecionados, intercalados com siltítos e argilitos e um membro superior constituído por lentes de arenitos finos, avermelhados, intercalados em siltítos e argilitos arroxeados (SCHNEIDER et al., 1974).

A Formação Serra Geral se faz representar por um sill básico de extensão regional. 0 relevo do tipo mesa é resultado de processos de intemperismo e erosão que atuaram sobre estas rochas de resistência diferencial. São encontrados nos Morros Cechinel e Casagrande (SILVA; LEITES, 2000).

O terceiro domínio geomorfológico presente é o dos Depósitos Sedimentares, com a unidades de Planícies Costeiras (litorâneas e colúvio aluvionares), ocupando a porção sul da área, ancorada sobre rochas do embasamento cristalino e da bacia do Paraná. Ali ocorrem importantes formações lacustres, associadas às numerosas lagunas da região (SILVA; LEITES, 2000). Os Depósitos Aluvionares possuem areias e lamas, eventualmente em cascalheiras, que preenchem as calhas dos rios e suas planícies de inundação. São expressivos e predominantemente argilosos ou areno-siltico-argilosos.

Na porção norte do município, predominam afloramentos das litologias areníticas correspondentes a formação Rio Bonito, sendo esta a portadora dos intervalos carbonosos existentes na bacia do Paraná. Nesta porção do município são comuns a presença de bocas de mina nas encostas das escarpas onde afloram as camadas de carvão. Na porção sul, predominam as litologias pelíticas da Formação Palermo, estratigraficamente sotoposta da Formação Rio Bonito, nestas, a mineração de carvão ocorreu/ocorre de forma subterrânea, portanto, seus locais impactadas em superfície são decorrentes das operações de lavra (DIAS, 1995).

Em se tratando da hidrogeologia, podem se destacar quatro diferentes domínios relacionados às litologias aflorantes na área de estudo. Com uma tipologia de aquífero poroso intergranular, temos o domínio composto pelas litologias areníticas da Formação Rio Bonito e os sedimentos inconsolidados Cenozoicos arenosos à cascalhosos relacionados a depósitos costeiros e aluviais recentes. Além destes, ocorrem na área aquíferos fraturados relacionados aos basaltos e diabásios da formação Serra Geral e os aquíferos/aquitardos porosos/fraturados relacionados as rochas pelíticas da Formação Palermo.

A unidade Hidroestratigráfica Rio Bonito compõe um aquífero com porosidade intergranular composto por arenitos finos, cinza-amarronzados, mal selecionados e localmente conglomerados cinza-claros. Secundariamente ocorrem folhelhos, argilito e siltito cinza-escuro a pretos. A estruturação é por estratificações paralelas, cruzadas tabulares e acanaladas. A espessura pode ultrapassar os $300 \mathrm{~m}$, compondo aquíferos do tipo semiconfinado a confinado de extensão regional, com porosidade intergranular ampliada por fraturamento, descontínuo, heterogêneo e anisotrópico (MACHADO, 2013).

Já a unidade Hidroestratigráfica Cenozoica é composta por sedimentos marinhos e costeiros são representados por sucessões de camadas arenosas, pouco ou não-consolidadas. Apresenta-se como aquífero livre de extensão regional, com porosidade intergranular, contínuo, homogêneo e isotrópico. Os terrenos ocupados por esta zona aquífera estão relacionados com a sedimentação marinha e em alguns casos, remobilização eólica em barreiras, caracterizando-se por constituírem-se em planícies com altitude média de $10 \mathrm{~m}$. Ainda dentro desta, ocorrem aquíferos livres de menor permeabilidade, com extensão regional, com porosidade intergranular, contínua, homogêneo e anisotrópico relacionados a depósitos aluviais e coluviais (MACHADO, 2013).

Dentro do domínio dos aquíferos fraturados, ocorrem os aquíferos relacionado às litologias vulcânicas intrusivas presentes. Sendo essas intrusivas vulcânicos basálticos típicas intertrapeadas em litologias da Bacia do Paraná. Este compartimento é caracterizado por aquíferos livres a semiconfinados de extensão local, com porosidade por fraturamento, descontínuo, heterogêneo e anisotrópico (MACHADO, 2013). Este domínio é composto segundo Machado (2013) pela sucessão de litologias pelíticas onde raramente ocorrem aquíferos localizados restritos a zonas fraturadas (MACHADO, 2013).

As águas superficiais do município de Criciúma drenam para as bacias hidrográficas do Araranguá e Urussanga (Figura 3B), ambas pertencentes a $10^{\text {a }}$ Região Hidrográfica do Estado de Santa Catarina. (SANTA CATARINA, 1997). 


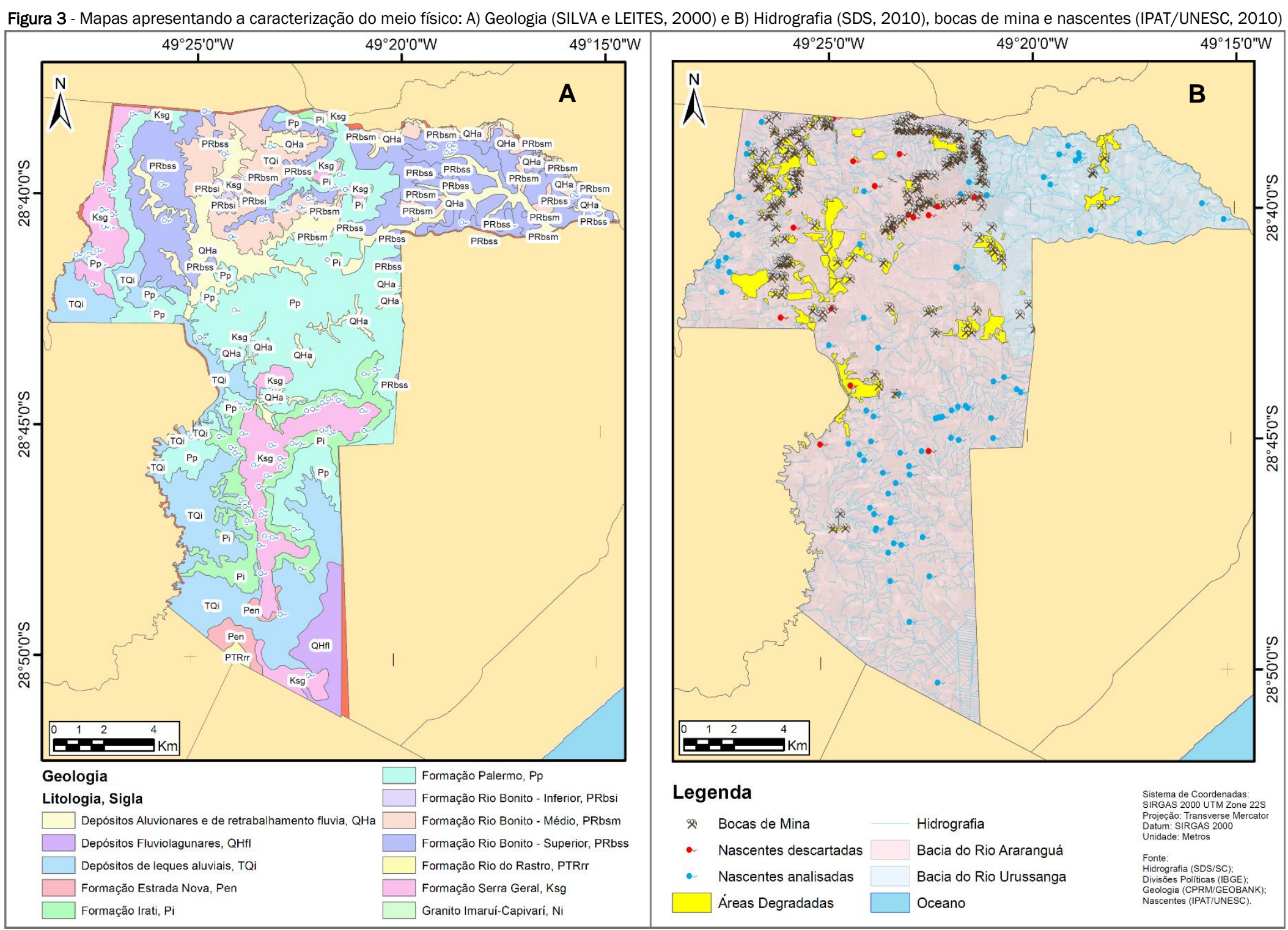


Em relação a rede hidrográfica da área de estudo, os diversos cursos d'água que compõem a hidrografia do município são tributários de duas diferentes bacias hidrográficas, sendo que a Bacia do Rio Araranguá, compreende cerca de $75 \%$ do território do município enquanto e a bacia do Rio Urussanga, cerca de 25\% (IPAT/UNESC, 2010).

\subsection{Pontos Analisados}

O conjunto de resultados analíticos utilizado foi composto por análises físico-químicas de 100 nascentes do município de Criciúma/SC (GALATTO et al., 2011). Do conjunto global de pontos foram selecionados 83 , considerados livres de interferência por atividades relacionadas à mineração de carvão e desta forma confiáveis do ponto geoquímico para avaliação do background.

A seleção das nascentes foi realizada, em ambiente SIG, a partir da sobreposição dos mapas das áreas impactadas pela mineração de carvão no município. Foram consideradas as áreas degradadas em superfície e as embocaduras de antigas minas de encosta nas porções onde a camada de carvão era aflorante. A partir desta avaliação prévia foram identificadas 17 nascentes sob influência de DAM, as quais foram excluídas da análise estatística.

\subsection{Métodos Estatísticos}

Os valores de background das nascentes da região de Criciúma foram estimados com o método EDA (Exploratory Data Analysis), utilizado na determinação de parâmetros em prospecção geoquímica (TUKEY, 1977; CHIPRÉS, et al., 2009).

O Método EDA foi introduzido para analisar dados que não seguem um modelo normal e consiste de um conjunto de estatísticas descritivas e, principalmente, ferramentas gráficas que visam ganhar o máximo de informações sobre os dados e também determinar outliers e anomalias. Pelo método da boxplot se define IQR-Inter Quartil e Range como a diferença en- tre o terceiro e o primeiro quartis. Os quartis superior e inferior, referidos como hinges, definem a caixa central, que contém aproximadamente $50 \%$ dos dados. 0 inner fence é definido como uma caixa estendida por 1,5 vezes o comprimento da caixa em direção ao máximo e ao mínimo. Os valores que estão nos extremos das inner fences são os whiskers. Quaisquer valores fora do intervalo das whiskers são definidos como outliers, que nas águas subterrâneas podem ser interpretados como anômalos que compõem o background da região. Define-se a LIF (lower inner fence) e a LOF (lower outer fence) respectivamente como valendo 1,5 x IQR e 3 x IQR além da lower hinge em direção ao valor mínimo. Também se definem UIF (upper inner fence) e UOF (upper outer fence) como valendo respectivamente 1,5 x IQR e 3 x IQR além da uppe rhinge na direção do valor máximo. A UIF é usualmente considerada o limite separando valores de background e anomalias, embora a UOF também possa ser usada como limite.

De forma complementar, foi utilizada a técnica de uso de frequências acumuladas, também conhecidas por somas cumulativas, de acordo com o método proposto por Lepeltier (1969) e modificado por Matschullat et al. (2000). Este se baseia no pressuposto de que concentrações de elementos possuem uma distribuição log-normal, ou seja, se utiliza da ideia de que a distribuição de elementos segue distribuição normal (ou de Gauss).

Projetando-se as "somas cumulativas vs. concentração do elemento", em escala bilogarítmica, um desvio da distribuição log-normal pode ser percebido como uma inflexão na parte superior da curva, representando uma anomalia (LEPELTIER, 1969; MATSCHULLAT et al., 2000), conforme demonstrado na . Nesta, conforme descrito por Rodrigues e Nalini Jr. (2009), as duas setas apontam para dois momentos decisivos que separam os valores de background de um dado elemento $(0$ $70 \%)$ de amostras que possuem, naturalmente, concentrações elevadas do elemento ( $70-90 \%)$ e de amostras que sofrem influência antropogênica (>90 - 100\%).

Figura 4 - Projeção bilogarítmica segundo Rodrigues e Nalini Jr. (2009)

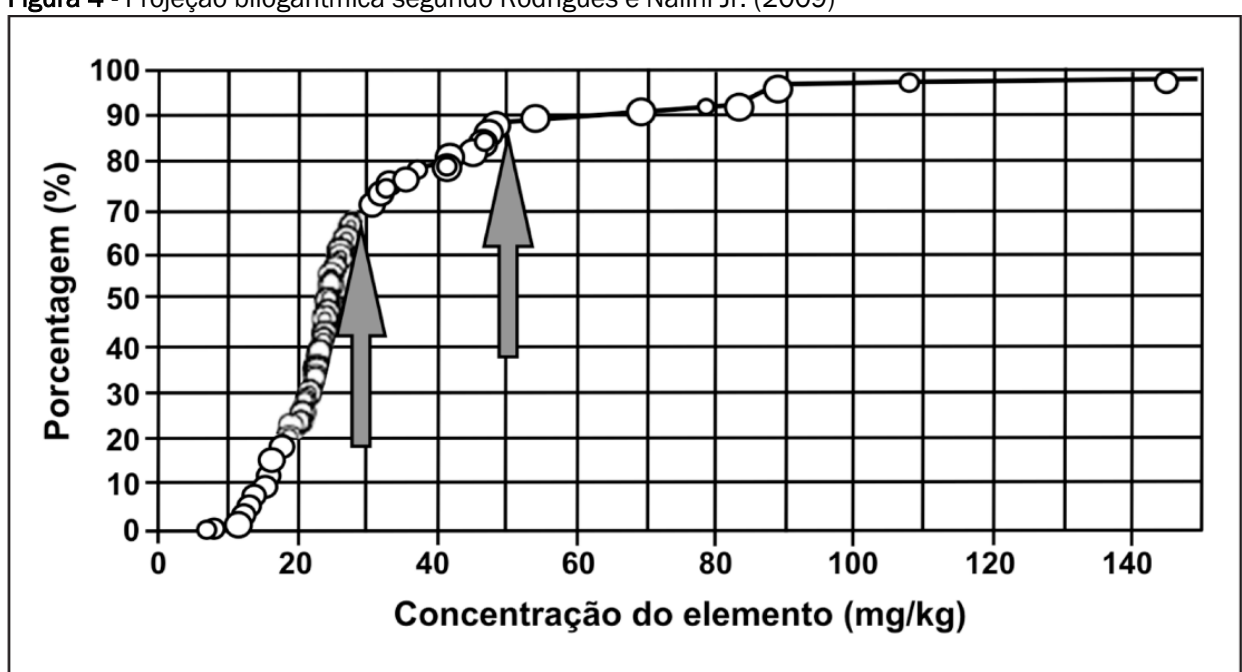




\section{RESULTADOS E DISCUSSÕES}

\subsection{Análise de Dados}

Dentre o conjunto de análises disponível para o presente estudo, 17 foram consideradas impróprias para utilização durante a análise estatística realizada para a determinação do background local. Esta definição se deu por meio da análise, em ambiente SIG, quando comparada a correlação espacial entre a localização de cada nascente em relação as potenciais fontes de contaminação (áreas impactadas em superfície e bocas de mina a montante das nascentes avaliadas).

A análise estatística realizada com os dados analíticos $\mathrm{pH}$, ferro, manganês e sulfato permitiu a determinação das concentrações médias, além de outras variáveis importantes destes parâmetros analíticos de monitoramento, e os respectivos valores de background das nascentes da área estudada (Tabela 1).

Em relação ao $\mathrm{pH}$, foi registrado para o conjunto de dados avaliados ( $n=83$ ) uma variação de 5,1 a 7,7 com uma mediana de 6,3. Aplicando-se as técnicas do EDA, observa-se que o pH apresenta um limite inferior de 5,5 e um superior de 7,9 e podendo este ser considerada intervalo para background.

Da mesma forma, em se tratando do parâmetro ferro, obtevese na análise do conjunto de dados uma mediana de $0,88 \mathrm{mg} / \mathrm{L}$, com uma variação entre $0,02 \mathrm{mg} / \mathrm{L}$ e $7,3 \mathrm{mg} / \mathrm{L}$. A partir da aplicação do EDA ao conjunto encontrou-se como concentração máxima o valor de $2,58 \mathrm{mg} / \mathrm{L}$, podendo ser considerados anômalos concentrações superiores a este limite.

Quanto ao metal manganês, este apresentou concentrações em um range que variou de $0,01 \mathrm{mg} / \mathrm{L}$ a $1,26 \mathrm{mg} / \mathrm{L}$, com uma mediana de 0,08mg/L. Em termos de resultados do EDA, este metal apresentou como valor máximo a ser considerado não anômalo a concentração de 0,30mg/L.

O último parâmetro analítico a ser apreciado pela técnica do EDA foi o sulfato e para este foram encontradas concentrações mínimas e máximas de $<10,00$ e $88,00 \mathrm{mg} / \mathrm{L}$, respectivamente, com uma mediana de 5,00mg/L. Assim, pode-se considerar como limite superior do background geoquímico a concentração de $20 \mathrm{mg} / \mathrm{L}$.

Tabela 1 - Resultado das análises estatísticas dos parâmetros analíticos avaliados, com destaque para o background geoquímico

\begin{tabular}{|c|c|c|c|c|c|}
\hline & & $\mathrm{pH}$ & Ferro & $\begin{array}{c}\text { Manganês } \\
\mathrm{mg} / \mathrm{L}\end{array}$ & Sulfatos \\
\hline \multirow{5}{*}{$\begin{array}{l}\text { Parâmetros } \\
\text { descritivos }\end{array}$} & Média & 6,4 & 0,88 & 0,12 & 11,37 \\
\hline & Mediana & 6,3 & 0,31 & 0,08 & $<10,00$ \\
\hline & Desv.Pad & 0,59 & 1,27 & 0,17 & 14,62 \\
\hline & Mínimo & 5,1 & 0,02 & 0,01 & 5,00 \\
\hline & Máximo & 7,7 & 7,30 & 1,26 & 88,00 \\
\hline \multirow{5}{*}{$\begin{array}{c}\text { Parâmetros } \\
\text { EDA }\end{array}$} & $1^{\circ}$ quartil & 5,90 & 0,12 & 0,03 & 5,00 \\
\hline & $3^{\circ}$ quartil & 6,70 & 1,11 & 0,14 & 11,00 \\
\hline & IQR & 0,80 & 0,99 & 0,11 & 6,00 \\
\hline & $\mathrm{Q}^{3}+1,5 \mathrm{IQR}^{1}$ & 7,90 & 2,58 & 0,30 & 20,00 \\
\hline & Q1-1,5 IQR² & 5,50 & 0,00 & 0,00 & 2,00 \\
\hline
\end{tabular}

${ }^{1}$ Representa o limite superior do background ; ${ }^{2}$ Representa o limite inferior do background

Ao se relacionar os dados de $\mathrm{pH}$ registrados para o conjunto de dados $(n=83)$ a projeção bilogarítmica da "soma cumulativa vs. concentração" verifica-se que os dados formam uma curva gaussiana quase perfeita, nesta, os limites destacados por setas vermelhas na Figura $5 \mathrm{~A}$, ficam entre valores de $\mathrm{pH}$ de 5,6 a 7,2 .

Quanto a curva do elemento ferro (Figura 4B), dois desvios são claros na curva cumulativa, um em $0,5 \mathrm{mg} / \mathrm{L}$, indicando que até esta concentração encontra-se a porção predominante da população analisada. Outra inflexão ocorre entre os valores de 2,5 e 3,0mg/L. A interpretação deste gráfico apresenta valo- res em consonância com o obtido no EDA. A curva referente às concentrações de manganês apresenta um desvio entre as concentrações 0,3 e $0,4 \mathrm{mg} / \mathrm{L}$ (Figura $4 \mathrm{C}$ ), informação que corrobora o dado obtido no EDA.

O parâmetro sulfato registra um predomínio de concentrações menores que 10,0 mg/L (Figura 4D), o qual representa o limite de quantificação do método analítico utilizado. Neste sentido, descartando-se esta anomalia analítica, fica evidente um decréscimo das concentrações entre 15 e $20 \mathrm{mg} / \mathrm{L}$, indicativo de uma quebra de população. 
Figura 4 - Histogramas de "soma cumulativa vs. Concentração" dos parâmetros avaliados
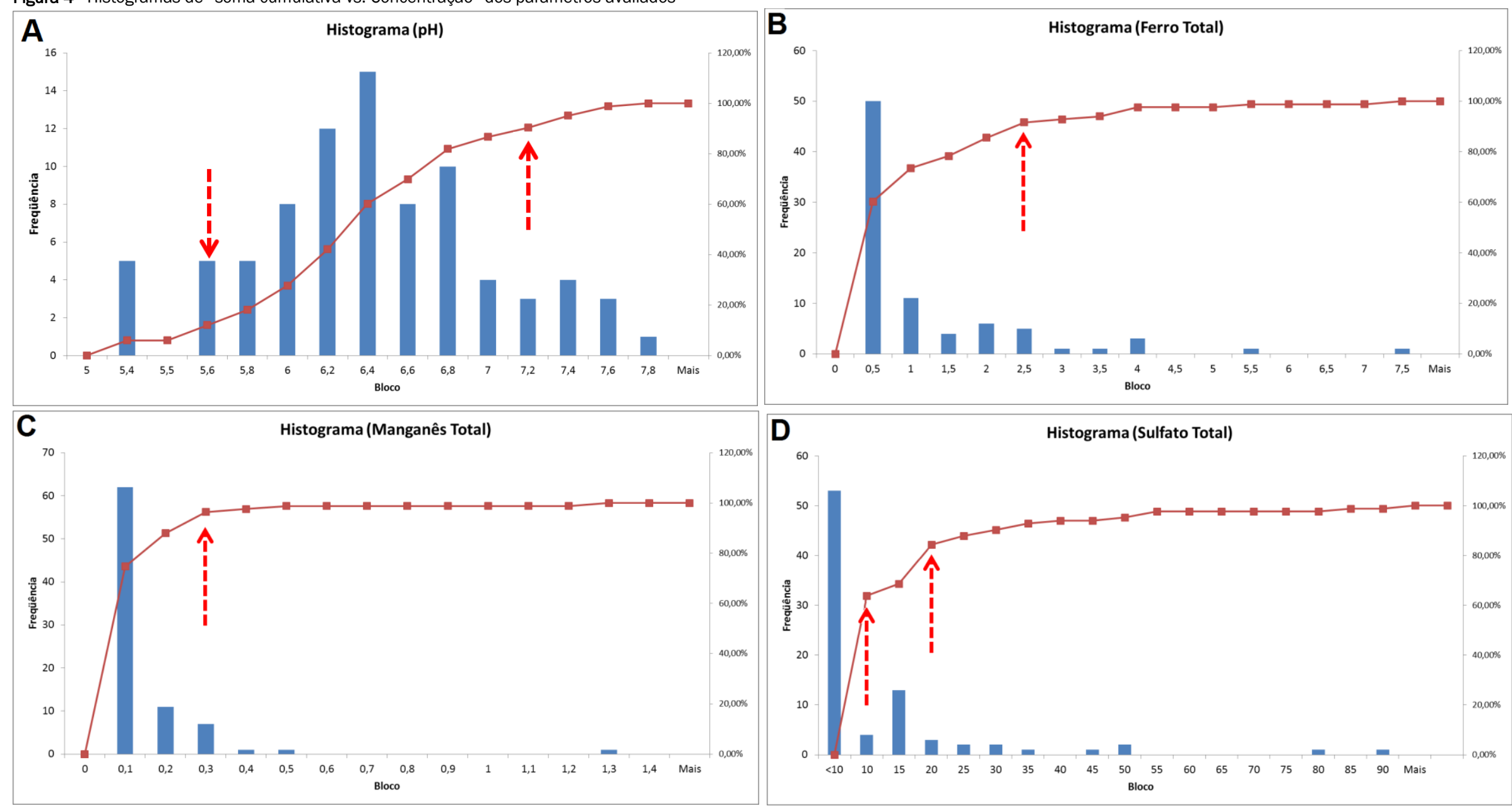
Quando se analisa os valores de background obtidos em comparação as legislações que versam sobre água subterrânea e água para consumo humano, fica evidente que os valores de fundo para a área (Tabela 2) em alguns casos suplantam as concentrações estabelecidas nestas legislações. 0 caso do manganês é emblemático, pois o limite superior para a concentração de background deste elemento ultrapassa os valores orientativos preconizado pelo Anexo XX da Portaria de Consolidação MS n. 5/2017 que versa sobre potabilidade de água.

Tabela 2 - Comparativo entre os valores obtidos no EDA e as legislações que versam sobre a temática água

\begin{tabular}{lcccc}
\hline & pH & Ferro & Manganês & Sulfatos \\
\hline background sup. (Q3 + 1,5 IQR) & & 2,58 & 0,30 & 20,00 \\
background inf. (Q3 - 1,5 IQR) & 7,90 & 0,00 & 0,00 & 2,00 \\
Res. CONAMA n. 357/20051 & 5,50 & 5,0 & 0,5 & 250 \\
Res. CONAMA n. 396/20082 & - & $0,3-5,0$ & $0,05-0,2$ & $250-1.000$ \\
Portaria MS n. 5/20173 & - & 0,3 & 0,1 & 250 \\
\hline
\end{tabular}

${ }^{1}$ Água superficial classe 3 e consumo humano; ${ }^{2}$ Água subterrânea; ${ }^{3}$ Potabilidade

\section{CONCLUSÕES}

Do conjunto de amostras de água de nascentes utilizadas para análise, $17 \%$ delas foram desconsideradas na análise estatística por sua correlação espacial ou química com impactos negativos de atividades da cadeia produtiva de carvão.

$\mathrm{Na}$ análise dos dados, aplicando-se a metodologia do EDA, ficou atestado que valores para $\mathrm{pH}$ encontrados dentro do intervalo que vai de 5,50 até 7,90 podem ser considerados como naturais para a água subterrânea no município. Os metais ferro e manganês, apresentaram concentrações superiores de background de 2,58 e 0,30mg/L respectivamente. Já o sulfato, apresentou como background para a água subterrânea o intervalo de concentrações entre 2,00 e 20,00mg/L.

No trabalho ficaram evidentes questões importantíssimas em se tratando da característica natural das águas subterrâneas no território da cidade de Criciúma, a mais importante, é o fato de que as concentrações dos parâmetros avaliados em muitos casos podem naturalmente suplantar limites legalmente regulamentados, o que indica que mesmo águas sem impacto antrópico podem encontrar-se impróprias para uso. Este fato se faz notável no caso do metal manganês, que apresenta uma concentração de background superior três vezes ao preconizado pela Portaria de consolidação MS n. 5/2017 que versa sobre potabilidade de água.

\section{REFERÊNCIAS}

ALEXANDRE, N. Z. Influência da mineração de carvão na qualidade das águas superficiais - Revisão Bibliográfica. Revista Tecnologia e Ambiente, v. 2, n. 1, p. 53-61, 1996.

BRASIL. Decreto n 85.206 de 25 de setembro de 1980. D.O.U. de 25/10/1980. Disponível em: http://www2.camara.leg.br/legin/fed/decret/1980-1987/decreto-8520625-setembro-1980--434622-publicacaooriginal-1-pe.html. Acesso em: 13 fev. 2019.
BRASIL. Conselho Nacional de Meio Ambiente - CONAMA. Resolução CONAMA $n^{\circ} 357$. Dispõe sobre a classificação dos corpos de água e diretrizes ambientais para o seu enquadramento, bem como estabelece as condições e padrões de lançamento de efluentes, e dá outras providências. Diário Oficial da União, Brasília, 17 mar. 2005, p. 58-63.

BRASIL. Conselho Nacional de Meio Ambiente - CONAMA. Resolução CONAMA $n^{\circ}$ 396. Dispõe sobre a classificação e diretrizes ambientais para o enquadramento das águas subterrâneas e dá outras providências. Diário Oficial da União, Brasília, n. 66, 7 abr. 2008, Seção 1, p.64-68.

BRASIL. Conselho Nacional de Meio Ambiente - CONAMA. Resolução $n^{\circ} 420$. Dispõe sobre critérios e valores orientadores de qualidade do solo quanto à presença de substâncias químicas e estabelece diretrizes para o gerenciamento ambiental de áreas contaminadas por essas substâncias em decorrência de atividades antrópicas. Diário Oficial da União, Brasília, 30 dez. 2009.

BRASIL. Conselho Nacional de Meio Ambiente - CONAMA. Resolução $n^{\circ} 454$. Estabelece as diretrizes gerais e os procedimentos referenciais para o gerenciamento do material a ser dragado em águas sob jurisdição nacional. Diário Oficial da União, Brasília,1 nov. 2012.

BRASIL, Ministério da Saúde. Portaria de consolidação N ${ }^{\circ} 5$. Consolidação das normas sobre as ações e os serviços de saúde do Sistema Único de Saúde. Diário Oficial da União, Brasília,5 set. 2017.

CAMPOS, M.L.; ALMEIDA, J.A.; SOUZA, L.S. Avaliação de três áreas de solo construído após mineração de carvão a céu aberto em Lauro Müller, Santa Catarina. Revista Brasileira de Ciência do Solo, v. 27, p.1123-1137, 2003.

CHIPRÉS, J.A., CASTRO-LARRAGOITIA B.A.J., MONROY, M.G.,.Exploratory and spatial data analysis (EDA-SDA) for determining regional background levels and anomalies of potentially toxic elements in soils from Catorce-Matehuala, Mexico. Applied Geochemistry, v. 24, p. 1579-1589, 2009. 
DIAS, A.A. Geologia do Município de Criciúma, SC. Porto Alegre: CPRM. (Série Cartas Temáticas - Porto Alegre, v. 23). (Programa de Informações Básicas para a Gestão Territorial de Santa Catarina), 1995.

GALATTO, S.L.; ALEXANDRE, N.Z.; PEREIRA, J.L.; PATRÍCIO, T.B.; VASSILIOU, M.; FERNANDES, A.N.; FRASSETTO, J.; VALVASSORI, M.L. Diagnóstico ambiental de nascentes no município de Criciúma, Santa Catarina. Revista de Ciências Ambientais, v.5, p.39-56, 2011.

GAPLAN/SC. Atlas de Santa Catarina. Rio de Janeiro: Aerofotos Cruzeiro, 1986. 173p.

GOMO, M, VERMEULEN, D,. Investigation of hydrogeochemica processes in groundwater resources located in the vicinity of a mine process water dam. Journal of African Earth Sciences, v. 86, p. 119-128, 2013.

IPAT/UNESC, Instituto de Pesquisas Ambientais e Tecnológicas - Universidade do Extremo Sul Catarinense. Projeto Nascentes: $1^{a}$ Etapa, Município de Criciúma. Relatório Final. Criciúma, 2010. 78 p.

LEPELTIER, C. A simplified treatment of geochemical data by graphical representation. Economic Geology, v. 64, p. 538550, 1969

MACHADO, J. L. F. Mapa Hidrogeológico do Estado de Santa Catarina. Escala 1:500.000. Programa de Disponibilidade Hídrica do Brasil. CPRM. Porto Alegre. 1 mapa. 2013.

MATSCHULLAT, J., OTTENSTEIN, R., REIMANN, C. Geochemica background - can we calculate it. Environmental Geology, v. 39, p. 990-1000, 2000

RAVAZZOLLI, Claúdia. A problemática ambiental do carvão em Santa Catarina: sua evolução até os termos de ajustamento de conduta vigente entre os anos de 2005 e 2010. Geografia em questão. v. 6, n. 1, p.179-201, 2013.
RODRIGUES, A.S de Lima \& NALINI Jr., H.A. Valores de background geoquímico e suas implicações em estudos ambientais. REM: Revista da Escola de Minas, v. 62, n. 2, p. 155165, 2009.

SANTA CATARINA. Secretaria do Estado de Meio Ambiente. Bacias hidrográficas de Santa Catarina: diagnóstico geral. Florianópolis: SDM, 1997.

SCHNEIDER, C. H. Controle da drenagem ácida de minas na mineração de carvão de Santa Catarina: caso da Mina UMII Verdinho. Dissertação de Mestrado do PPGE3M, UFRGS, Porto Alegre-RS, 2006. 133p.

SCHNEIDER, R.L., MÜHLMANN, H., TOMMASI, E., MEDEIROS, R.A., DAEMON, R.F. \& NOGUEIRA, A.A.. Revisão Estratigráfica da Bacia do Paraná. In: CONGRESSO BRASILEIRO DE GEOLOGIA, 28., 1974, Porto Alegre. Anais... Porto Alegre, SBG, v.1, p. 41-66. 1974.

SECRETARIA DE ESTADO DO DESENVOLVIMENTO SUSTENTÁVEI - SDS. Hidrografia do município de Criciúma-SC, 2010. Disponível em: http://sigsc.sds.sc.gov.br/. Acesso em: 13 fev. 2019.

SILVA, M. A. S.; LEITES, S. R. Folha SH.22-X-B, Criciúma: escala 1:250.000. Programa de Levantamentos Geológicos Básicos do Brasil - PLGB. Brasília: CPRM, 2000.

TUKEY, J. W. Exploratory data analysis. Addison-Wesley, Reading, MA. 1977.

UNITED STATES ENVIRONMENTAL PROTECTION AGENCY USEPA. Soil screening guidance: User's guide - EPA 450/R96/018. Washington, Office of Solid Waste and Emergency Response, 1996.

VROM. Intervention values and target values: Soil quality standards. The Hague, 1994. 19p. (DBO/07494013) 